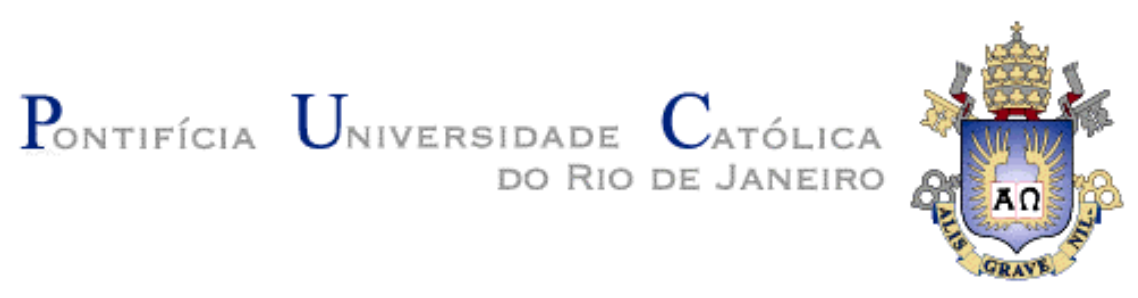

Cláudia Hernandez Barreiros

Quando a diferença é motivo de tensão - um estudo de currículos praticados em classes iniciais do ensino fundamental

Tese de Doutorado

Tese apresentada ao Programa de Pós-Graduação em Educação da PUC-Rio como requisito parcial para a obtenção do título de Doutora em Educação.

Orientadora: Vera Maria Ferrão Candau 


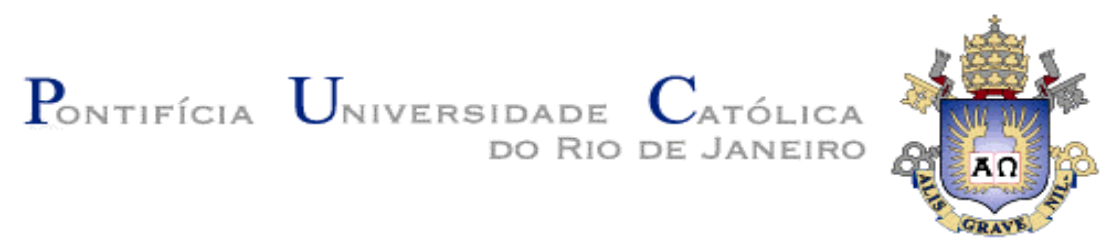

Cláudia Hernandez Barreiros

\title{
Quando a diferença é motivo de tensão \\ - um estudo de currículos praticados em classes iniciais do ensino fundamental
}

\begin{abstract}
Tese apresentada ao Programa de Pós-Graduação em Educação da PUC-Rio como requisito parcial para a obtenção do título de Doutora em Educação. Aprovada pela Comissão Examinadora abaixo assinada
\end{abstract}

\author{
Prof ${ }^{a}$ Vera Maria Ferrão Candau \\ Orientadora \\ Departamento de Educação - PUC-Rio
}

Prof ${ }^{\text {S Sonia Kramer }}$

Departamento de Educação - PUC-Rio

Prof ${ }^{a}$ Isabel Alice Oswald Monteiro Lelis Departamento de Educação - PUC-Rio

Prof ${ }^{\mathrm{a}}$ Carmen Teresa Gabriel Anhorn Faculdade de Educação da UFRJ

Prof Antonio Flávio Barbosa Moreira Faculdade de Educação da UCP

Prof Paulo Fernando Carneiro de Andrade Coordenador Setorial do Centro de Teologia e Ciências Humanas PUC-Rio

Rio de Janeiro, maio de 2006 
Todos os direitos reservados. É proibida a reprodução total ou parcial do trabalho sem autorização da universidade, da autora e da orientadora.

\section{Cláudia Hernandez Barreiros}

Licenciou-se em Pedagogia - Magistério das Disciplinas Pedagógicas do $2^{\circ}$ Grau - em 1990; especializou-se em Orientação e Supervisão Educacional, em 2000 e cursou Mestrado em Educação, em 1997: todos esses cursos realizados na Universidade do Estado do Rio de Janeiro - UERJ. Sua dissertação intitula-se Alfabetização e poder na escola - um estudo de livros didáticos usados na formação do/a professor/aalfabetizador/a. Vem participando de diversos encontros na área de educação, como reuniões anuais da ANPED, ENDIPEs e COLEs. É professora do Instituto de Aplicação Fernando Rodrigues da Silveira - CAp/UERJ - e dos cursos de pedagogia das universidades Estácio de Sá e UniverCidade.

Ficha catalográfica

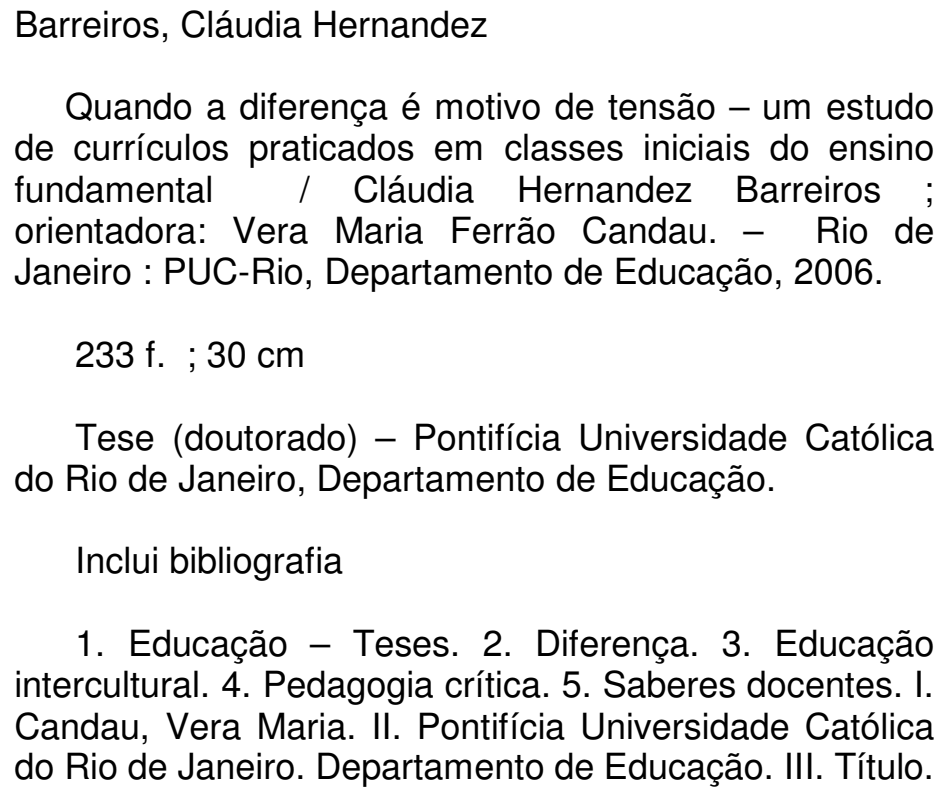

1. Educação - Teses. 2. Diferença. 3. Educação intercultural. 4. Pedagogia crítica. 5. Saberes docentes. I. Candau, Vera Maria. II. Pontifícia Universidade Católica do Rio de Janeiro. Departamento de Educação. III. Título. 


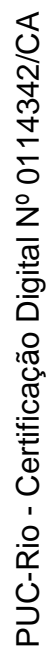

Às minhas colegas professoras $e$ às minhas alunas e alunos 


\section{Agradecimentos}

À minha orientadora, Professora Vera Maria Ferrão Candau. Sem seu estímulo, sua boa vontade e sua amizade, eu não teria chegado aqui.

À CAPES e à PUC-Rio, pelos auxílios concedidos, sem os quais este trabalho não poderia ser realizado.

À banca examinadora, que muito contribuiu com suas observações e apoio durante os exames de qualificação I e II, para não mencionar o papel dessas/es docentes ao longo de toda a minha formação.

Às professoras e aos professores do departamento de Educação da PUC-Rio pelas ótimas aulas que me proporcionaram, fazendo-me crer cada vez mais que a paixão pela educação não cabe somente às professoras e aos professores da educação básica.

Às professoras e à equipe técnica da Escola $M a K u x i$, pelo carinho, atenção e imenso profissionalismo com que me receberam. Em certa medida, elas se fazem co-autoras deste trabalho.

Às amigas e aos amigos do GECEC pela cumplicidade, ricas trocas de idéias e pelo apoio. Carinho especial à Adélia, que me colocou no rumo e me fez ver a possibilidade de um ponto final, quando eu só enxergava reticências.

Às colegas do Departamento de Ensino Fundamental e do CAp/UERJ pelo apoio e cumplicidade durante todos os anos do curso.

À minha mãe e ao meu pai: meus amigos, meu refúgio, minha estrutura, meu aconchego, meus amores de sempre!

Ao meu filho Thor, amor de há pouco tempo, motivo maior para eu seguir tentando!

Às amigas e aos amigos antigas/os e novas/os, que me apoiaram nos momentos difíceis da vida que continua acontecendo, mesmo quando a gente está cursando um doutorado: Jonê, Daniela, Sônia, Márcia, Paulo, Rosane, Néa, João, Ivone, Dinalva, Adriano, Jacqueline, Rita, Débora, Leila, Hector, Malu, Maria Rita, Rafael e muitas/os outras/os cujos nomes não caberiam nessa página: valeu!

E, é claro, a Deus, que se mostrou para mim em todos os momentos, através desses seres humanos, meus irmãos e irmãs. 


\section{Resumo}

Barreiros, Cláudia Hernandez e Candau, Vera Maria Ferrão. Quando a diferença é motivo de tensão - um estudo de currículos praticados em classes iniciais do ensino fundamental. Rio de Janeiro, 2006. 233p. Tese de Doutorado Departamento de Educação, Pontifícia Universidade Católica do Rio de Janeiro.

Nesta pesquisa de inspiração etnográfica, procurou-se conhecer e compreender de que forma o referencial teórico da diferença, trazido à escola e à formação de professoras via estudos sobre o fracasso escolar, foi incorporado nas práticas pedagógicas cotidianas de professoras dos anos iniciais do ensino fundamental. Foi investigada uma escola da rede pública municipal do Rio de Janeiro, localizada no interior de uma grande favela-bairro. O estudo contou com observações a reuniões de planejamento e centros de estudos, a aulas de quatro turmas e três professoras e também com entrevistas a essas três professoras e à diretora e à coordenadora pedagógica da escola. Considerou-se a princípio que a diferença é um tema que não exige apenas ações planejadas e conscientes, uma vez que também emerge em situações não previstas e que, quase sempre, implicam em tensão. Iniciou-se o estudo pela delimitação do que se entende por uma educação intercultural e, para isso, optou-se por tomar como autores/as de referência Peter McLaren, com seu multiculturalismo crítico e Vera Candau, com sua didática intercultural. Para compreender como as professoras constróem seus conhecimentos didáticos, optou-se por trabalhar com Maurice Tardif e sua noção de saberes docentes. Para lidar com a ação docente diante do inesperado e do imprevisto, escolheu-se Philippe Perrenoud e a noção de habitus profissional que ele aperfeiçoou. A partir daí, analisam-se o projeto pedagógico da escola apresentado pela equipe técnico pedagógica e discutido em algumas reuniões observadas, cenas do cotidiano da escola acompanhadas pela pesquisadora e as entrevistas feitas às professoras pesquisadas. Percebeu-se que a palavra diferença congrega variados sentidos e que alguns deles de fato estão presentes nessa escola e sendo enfrentados por essas professoras em suas atividades como docentes, mas que a perspectiva cultural abordada por McLaren, Candau e outros e procurada 
pela pesquisadora somente apareceu nos momentos de estudo do tema pelo grupo de docentes. Nesse sentido, acredita-se que ainda há muito o que investir em políticas de formação docente para que esse referencial, pelo seu viés cultural e numa perspectiva crítica, penetre as práticas pedagógicas.

\section{Palavras-chave:}

Diferença, educação intercultural, pedagogia crítica, saberes docentes. 


\section{Abstract}

Barreiros, Cláudia Hernandez e Candau, Vera Maria Ferrão. When difference is a source of tension - a study of the curricula being implemented in initial years of primary education. Rio de Janeiro, 2006. 233p. Tese de Doutorado - Departamento de Educação, Pontifícia Universidade Católica do Rio de Janeiro.

In this study of an ethnographic nature, we have sought to understand how a theoretical framework based on the concept of difference and introduced in schools and teacher education via studies on school failure has been incorporated into the daily pedagogic practice of teachers in charge of initial grades in primary education. We focused our investigation on a public school located in a large shantytown in Rio de Janeiro. The study included observation of planning sessions and study centers, of lessons given to four different classes by three different teachers, as well as interviews with the teachers, the coordinator and the school's headmistress. Our starting point was the idea that difference does not demand only planned, conscious action, once it also emerges in unplanned situations frequently generating tension. Another starting point is the concept of intercultural education. To this end, we have chosen to adopt Peter McLaren and his concept of critical multiculturalism as well as Vera Candau's idea of intercultural teaching practices as major theoretical references. To understand how teachers build up their pedagogical knowledge, we have chosen Maurice Tardif's notion of teacher knowledge. To analyse teachers' ways of coping with the unexpected, unplanned-for situations in their lessons, we have chosen Philippe Perrenoud's notion of professional habitus. From these theoretical perspectives, we have attempted to analyse the school's pedagogic project presented by the school's pedagogic team and debated at some staff meetings we had the opportunity to attend; some aspects of the school daily routine we were able to observe and the interviews with key staff. From these analyses, we have concluded that different meanings are attributed to the word difference, some of which are present in the school and are encountered by the teachers in their practice. However, the cultural perspective proposed by McLaren, Candau and other authors was only considered when it was the focus of a study group made up 
by the teachers. This observation led us to conclude that a lot of effort has yet to be invested into teacher education policies in order to promote the cultural and critical perspectives proposed by this theoretical framework so that it becomes incorporated into teaching practices.

\section{Key words} knowledge.

Difference, intercultural education, critical pedagogy, teachers' 


\section{Sumário}

Introdução - Como cheguei até aqui 13

Capítulo 1. Para uma pedagogia multi/intercultural 38

1. 1. Alguns percursos rumo à noção de diferença em educação 38

1. 2. A diferença na perspectiva multi/intercultural 41

1. 2. 1. Da Didática Fundamental à Didática Intercultural: percursos 41 de uma pesquisadora do campo

1. 2. 1. 1. O movimento da didática fundamental 42

1. 2. 1. 2. A(s) cultura(s) como um elemento fundamental da 45 didática

1. 2. 2. Diferença e desigualdade se implicam - primeira 53 aproximação com Peter McLaren

1. 2. 2. 1. Além da pedagogia crítica 56

1. 2. 2. 2. Para uma pedagogia crítica multiculturalmente orientada 59

1. 2. 2. 3. Para o empoderamento de Educadoras e Educadores 64

1. 2. 2. 4. De que professor/a precisa a pedagogia multicultural? 67

Capítulo 2. Uma pedagogia em construção nas práticas escolares: 69 itinerário de uma pesquisa

2. 1. A prática da pesquisa e seus fundamentos teóricos 69

2. 2. Uma noção sobre os saberes docentes 70

2. 2. 1. Investigar saberes docentes - questões metodológicas 78

2. 3. A noção de habitus e a formação de professoras/es 85

2. 3. 1. Recorrendo a Bourdieu 87

2. 4. Sistematizando os procedimentos de pesquisa 89

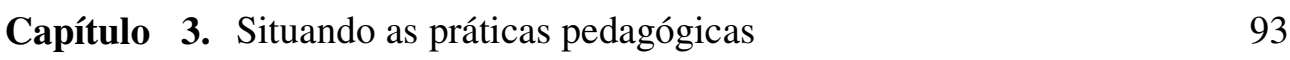

3. 1. Contextualizando a escola 93

3. 1. 1. A escola Ma Kuxi 93

3. 1. 2. A Maré a que a escola Ma Kuxi atende 97

3. 1. 3. O Projeto Político Pedagógico 102

3. 1. 4. Cenas do cotidiano 107

3. 1. 4. 1. Reuniões pedagógicas 107

3. 1. 4. 2. O pátio 131

3. 1. 4. 3. Salas de aula 132 
$\begin{array}{lll}\text { Capítulo 4. Práticas pedagógicas e sentidos da diferença } & 141\end{array}$

4. 1. As trajetórias profissionais das professoras e seus maiores 143 desafios

4. 2. Formas de desenvolvimento da sensibilidade para a questão da 152 diferença

4. 2. 1. Contribuições dos cursos de formação 153

4. 2. 2. Contribuições dos pares/colegas 157

4. 2. 3. Experiência como fonte 159

4. 3. Sentidos da diferença 162

4. 4. Preconceitos 172

4. 5. O fazer pedagógico e a diferença 177

Considerações ao final deste texto 186

Referências Bibliográficas $\quad 192$

Apêndice 1 - Roteiro das entrevistas 203

Apêndice 2 - Trechos selecionados do diário de campo 205 
O trabalho e o custo do sonho

Os sonhos de diferenciação não são como os sonhos que temos enquanto dormimos, instantes fugidos, imagens que atravessam nosso campo de consciência durante alguns segundos; é claro que o professor entrevê incessantemente coisas que deveriam ser feitas e logo as esquece, pressionado por outros problemas. Mas, com freqüência, ele vai ainda mais longe: reserva um tempo para refletir, para reexaminar os cadernos ou as provas, para reler os boletins redigidos para os pais ou as observações de seu registro. Ele segue sua idéia, a esquece, a reencontra, toma uma decisão, renuncia a ela por realismo, volta a ela por idealismo. O sonho só se apresenta como tal a posteriori. O professor vive mais um estado de dúvida, de hesitação, de reflexão, de formação de hipóteses ou de estratégia, de avaliação dos custos e dos benefícios, de pesquisa de informações e de soluções, de recordação do que já foi feito ou planejado. $O$ sonho é um trabalho do espírito. É aquilo que os psicanalistas destacam a propósito do que se trama no inconsciente. $\mathrm{O}$ sonho acordado também é um trabalho que leva tempo, mobiliza energia, torna-se indisponível para outra atividades. Mesmo se não leva a uma ação observável, ele existe, ocupa uma parte não desprezível da jornada de cada professor. Podemos observar isso melhor quando os professores trabalham em equipe e sonham juntos durante alguns momentos: as horas seguintes de discussão dão uma idéia do que passa pela cabeça de cada um deles quando está sozinho com seus alunos!

(Perrenoud, 2001: 40) 